\title{
SISTEM INFORMASI GEOGRAFIS PEMETAAN DAERAH RAWAN BENCANA SERTA JALUR EVAKUASI DI PADANG PARIAMAN
}

\author{
Heri Yanto, Romi Wijaya, Gisky Andria Putra \\ Universitas Putra Indonesia "YPTK”, Padang \\ email: heriyanto@upiyptk.ac.id
}

\begin{abstract}
Abstrak
Potensi bahaya (hazard) gempa bumi di Kota Pariaman cukup tinggi karena letaknya yang dekat dengan jalur patahan Semangko (Semangko Fault) atau patahan Barat Sumatera dan juga zona penujaman lempeng Palung Sunda yang dapat memicu terjadi gempabumi. Daerah penunjaman lempeng yang berada di dasar laut dapat berperan sebagai megathrust atau sesar anjak naik yang berpotensi untuk membangkitkan tsunami ketika terjadi gempa besar yang diikuti oleh deformasi vertical di lokasi tersebut.Wilayah Padang dan sekitar pantai Barat Sumatera merupakan dataran rendah yang memiliki resiko yang besar di dunia dari ancaman tsunami, yang dapat disebabkan oleh gempa bumi yang berasal dari Palung Sunda. Manajemen risiko harus fokus pada perlindungan penduduk dari gelombang tsunami dengan pemetaan yang cermat terhadap potensi wilayah yang terpapar dan objek penting dalam usaha mitigasi risiko yang tepat. Rencana mitigasi untuk pengelolaan bencana meliputi rekonstruksi dan langkahlangkah persiapan untuk kejadian bencana. Karena kita ketahui dari sumber bencana disebabkan oleh gempa bumi, zona-zona yang terkena dampak bencana ditentukan menggunakan sistem informasi geografis. Peta inundasi dibangun dengan sistem informasi geografis digunakan untuk berbagai keperluan. Potongan-potongan dari gedung dan lembaranlembaran jalan dan peta lembaran inundasi digunakan untuk mendeteksi gedung yang terkena gelombang tsunami, Lokasi penelitian berada di zona rawan gempa bumi, tsunami dan berjarak dekat dengan garis pantai.
\end{abstract}

Kata Kunci : Sistem Informasi Geografis, Pemetaan, Evakuasi 


\section{PENDAHULUAN}

Potensi bahaya (hazard) gempa bumi di Kota Pariaman cukup tinggi karena letaknya yang dekat dengan jalur patahan Semangko (Semangko Fault) atau patahan Barat Sumatera dan juga zona penujaman lempeng Palung Sunda yang dapat memicu terjadi gempabumi. Daerah penunjaman lempeng yang berada di dasar laut dapat berperan sebagai megathrust atau sesar anjak naik yang berpotensi untuk membangkitkan tsunami ketika terjadi gempa besar yang diikuti oleh deformasi vertical di lokasi tersebut.Wilayah Padang dan sekitar pantai Barat Sumatera merupakan dataran rendah yang memiliki resiko yang besar di dunia dari ancaman tsunami, yang dapat disebabkan oleh gempabumi yang berasal dari Palung Sunda, karena di wilayah tersebut terdapat seismic gapyang dapat menjadi sumber gempa di masa yang akan datang [1] Gempa bumi yang terjadi di Kota Pariaman dapat berasal dari zona penujaman dan patahan besar Sumatera. Gempa yang berasal dari zona penujaman/subduksi akibat dari tumbukan dua lempeng yaitu lempeng (Samudra) Hindia atau lempeng India-Australia bergerak menunjam ke bawah lempeng (benua) Sumatra dan busur kepulauan di bagian baratnya adalah bagian dari lempeng Eurasia [2]. Usaha mitigasi bencana di Kota Pariaman sangat diperlukan mengingat Kota Pariaman merupakan daerah pesisir di Sumatera Barat yang dekat dengan lokasi sumber gempa dan tsunami. Mitigasi tersebut dapat diwujudkan dengan membuat Pemetaan lokasi evakuasi di daerah pesisir yang dapat dijangkau dengan cepat oleh masyarakat saat akan terjadi tsunami (UU 24/2007, UU 27/2007, Perda Kota Pariaman No. 3/2010). Lokasi evakuasi secara umum dapat berupa daerah alami dataran tinggi, tanah tinggi buatan dan struktur baru yang di rancang tahan gempa dan tsunami [3] Pemetan lokasi evakuasi menggunakan teknologi Informasi Geografis. Teknologi informasi Geografis dapat mengelola tentang populasi, infrastruktur dan data distribusi spasial Misalnya, kemampuan untuk memberikan jawaban atas pertanyaan-pertanyaan penting, seperti di mana daerah yang paling terkena dampak dan bagaimana mencapainya dalam situasi darurat, dapat diatasi dengan menggunakan teknologi SIG [4]. Pengetahuan Ilmu Geografi digunakan dalam pengelolaan bencana untuk memandu dan memantau penggunaan lahan, menggambarkan rute transportasi untuk lokasi evakuasi yang efektif, dan menggambarkan kembali zona bahaya berdasarkan pengetahuan baru atau perubahan dalam sistem yang alami atau buatan manusia [5].

\section{TINJAUAN LITERATUR}

Rekayasa perangkat lunak adalah sebuah sistem yang memiliki komponen- komponen berupa perangkat lunak yang memiliki hubungan satu sama lain untuk memenuhi kebutuhan pelanggan. Sofware Program komputer yang terasosiasi dengan dokumentasi perangkat lunak seperti dokumentasi kebutuhan, model desain, dan cara penggunaan (user manual)[6]. Sebuah perangkat lunak juga sering disebut dengan sistem perangkat lunak. Sistem berarti kumpulan komponen yang saling terkait dan mempunyai satu tujuan yang ingin dicapai.Sistem perangkat lunak berarti sebuah sistem yang memiliki komponen berupa perangkat lunak yang memiliki hubugan satu sama lain untuk 
memenuhi kebutuhan pelanggan (customer).Pelanggan (customer) adalah orang atau organisasi yang memesan atau membeli perangkat lunak (sofware) dari pengembang perangkat lunak atau bisadianggap bahwa pelanggan (customer)adalah orang atau organisasi yang dengan sukarela mengeluarkan uang untuk memesan atau membeli perangkat lunak. User atau pemakai perangkat lunak adalah orang yang memiliki kepentingan untuk memakai atau menggunakan perangkat lunak untuk memudahkan pekerjaannya.

Perangkat lunak lebih merupakan elemen logika dan bukan merupakan elemen sistem fisik. Dengan demikian, perangkat lunak memiliki ciri yang berbeda dari perangkat keras yaitu :[7]

1. Perangkat lunak dibangun dan dikembangkan,tidak dibuat dalm bentuk yang klasik.

2. Perangkat lunak tidak pernah usang.

3. Sebagian besar perangkat lunak dibuat secara cutom-build, serta tidak dapat dirakit dari komponen yang sudah ada.

Sistem pendukung keputusan adalah sistem penghasil informasi yang ditujukan pada suatu masalah tertentu yang dipecahkan oleh manager dan dapat membantu manager dalam mengambil keputusan.[8] Sedangkan menurut (kadarih suryadi, dalam jurnal "Sri Eniyanti" 2011) adalah "suatu pendekatan sistematis pada hakekat suatu masalah, pengumpulan fakta-fakta penentu yang matang dari alternatif yang dihadapi dan pengambilan tindakan yang paling tepat". Algoritma Floyd-Warshall adalah salah satu varian dari pemrograman dinamis, yaitu suatu metode yang melakukan pemecahan masalah dengan memandang solusi yang akan diperoleh sebagai suatu keputusan yang saling terkait. Artinya solusi-solusi tersebut dibentuk dari solusi yang berasal dari tahap sebelumnya dan ada kemungkinan solusi lebih dari satu. Hal yang membedakan pencarian solusi menggunakan pemrograman dinamis dengan algoritma Greedy adalah bahwa keputusan yang diambil pada tiap tahap pada algoritma Greedy hanya berdasarkan pada informasi yang terbatas sehingga nilai optimum yang diperoleh pada saat itu. Jadi pada algoritma Greedy, kita tidak memikirkan konsekuensi yang akan terjadi seandainya kita memilih suatu keputusan pada suatu tahap.

Prinsip yang dipegangoleh pemrograman dinamis adalah prinsip optimalitas, yaitu jika solusi total optimal, maka bagian solusi sampai suatu tahap (misalnya tahap i ke i) juga optimal.

Graf atau graph merupakan struktur data yang paling umum. Jika struktur linear memungkinkan pendefinisian keterhubungan sekuensial antara entitas data, struktur data tree memungkinkan pendefinisian keterhubungan hirarkis, maka struktur graf memungkinkan pendefinisian keterhubungan tak terbatas antara entitas data. Definisi Graf adalah : 
$\mathrm{G}=(\mathrm{V}, \mathrm{E})$ yang dalam hal ini :

$\mathrm{V}=$ himpunan tak kosong dari simpul - simpul $=\{\mathrm{v} 1, \mathrm{v} 2, \mathrm{v} 3, \ldots\}$

$\mathrm{E}=$ himpunan sisi yang menghubungkan sepasang simpul $=\{\mathrm{e} 1, \mathrm{e} 2, \mathrm{e} 3,$.

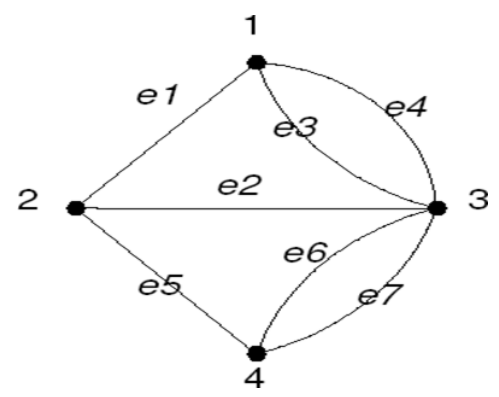

Gambar 1: Graf G

G adalah graf dengan :

$\mathrm{V}=\{1,2,3,4\}$

$\mathrm{E}=\{(1,2),(2,3),(1,3),(1,3),(2,4),(3,4),(3,4)\}$

$=\{\mathrm{e} 1, \mathrm{e} 2, \mathrm{e} 3, \mathrm{e} 4, \mathrm{e} 5, \mathrm{e} 6, \mathrm{e} 7\}$

Berdasarkan orientasi arah pada sisi, maka graf dibedakan atas 2 jenis :

1.Graf tak-berarah (undirected graph) Graf yang sisinya tidak mempunyai orientasi arah disebut graf tak-berarah

2.Graf berarah (directed graph atau digraph)Graf yang setiap sisinya diberikan orientasi arah disebut sebagai graf berarah.

\section{METODOLOGI}

Makna penelitian secara sederhana adalah bagaimana mengetahui sesuatu yang dilakukan melalui cara tertentu dengan prosedur yang sistematis. Maka penulis membentuk kerangka penelitian sebagai berikut : 


\begin{tabular}{|c|}
\hline Penelitian Pendahuluan \\
\hline Survei Penelitian \\
\hline Study Literatur \\
\hline Pengumpulan data \\
\hline $\begin{array}{c}\text { Rumusan Masalah } \\
\text { Tujuan Perumusan }\end{array}$ \\
\hline Analisa Tujuan \\
\hline Perumusan \\
\hline Perancangan \\
\hline
\end{tabular}

Gambar 2 : Kerangka Penelitian

\section{A.Tahapan Penelitian}

Tahapan penelitian ini menjelaskan langkah-langkah dalam melakukan pencatatan data serta mengumpulkan beberapa laporan yang di perlukan untuk dapat dijadikan pedoman dalam pembuatan penelitian ini, yaitu:

\section{Survei Penelitian}

Survei Melakukan pendekatan terhadap objek penelitian. Tujuan dari tahap ini adalah untuk mengetahui permasalahan yang terjadi secara tepat, sehingga diharapkan penelitian dapat memberikan solusi yang paling optimal terhadap pemecahan permasalahan tersebut, kamu melakukan Study Literatur yaitu mencari jurnal dan buku yang berkaitan dengan penerapan gis menggunakan algoritma Floyd Warshall dan menganalisis hasil dari penelitian tersebut.

\section{Pengumpulan Data}

Dalam melakukan proses pengumpulan data, penulis melakukan wawancara secara langsung ke Kabupaten Padang Pariaman dan di Badan Pusat Statistik(BPS) Kabupaten Padang Pariaman. Penulis mendapatkan informasi atau data yang di inginkan yaitu mengenai tentang persebaran penduduk, jalur jalan dan pembagian zona.

\section{A.Tempat Penelitian}


Penelitian yang dilakukan bertempat di Padang Pariaman terutama dipesisir pantai padang pariaman.

\section{Metode Penelitian}

Adapun metode penelitian yang dilakukan sebagai berikut:

a.Penelitian Lapangan

Penelitian lapangan dilakukan dimana penulis turun langsung mengambil data yang diperlukan, seperti mendapatkan data atau informasi dengan melakukan wawancara dan observasi.

b. Penelitian Pustaka

Penelitian yang dilakukan dengan menggunakan literatur (kepustakaan), baik berupa buku-buku, dan jurnal-jurnal, yang ada kaitannya dengan permasalahan yang dibahas.

\section{B.Observasi dan dokumentasi}

Metode observasi dan dokumentasi ini digunakan dalam rangka mengumpulkan data yang memberikan gambaran tentang situasi setempat atau social setting. Social setting diperoleh melalui observasi dan dokumentasi yaitu melihat data lapangan dan mendengar informasi dari informan, dan cerita warga setempat.

Metode observasi ini peneliti gunakan untuk memperoleh data yang berkaitan dengan: Aspek wilayah yang meliputi:

- Potensi daerah yang dapat dijadikan sebagai jalur evakuasi pasca bencana

- Siklus aktivitas masyarakat di Kota Padang Pariaman.

- Dan deskripsi ringkas lokasi penelitian.

Sedangkan Metode dokumentasi, digunakan untuk memperoleh data-data antara lain:

- Keadaan geografis daerah penelitian

- Data jumlah daerah padat penduduk yang rentan menimbulkan banyak korban jiwa serta tempat layanan publik yang diteliti.

- Catatan-catatan lainnya yang relevan dengan permasalahan penelitian.

Data yang diperoleh dari teknik observasi dan dokumentasi ini akan digunakan sebagai input bahan analisis spasial. Dengan adanya data ini sangatlah membantu penulis untuk menganalisa jalur evakuasi pasca terjadinya bencana dan didtribusi lahan terbuka di Kota Padang Pariaman. 


\section{HASIL DAN DISKUSI}

\subsection{Analisa Data}

Dalam melakukan digitalisasi peta dibutuhkan berbagai tahap sehingga peta yang digitalisasi sesuai dengan keadaan di lapangan sebenarnya. Dalam perancangan sistem ini digitalisasi peta dilakukan dengan menggunakan software MapInfo Professional 10.0. Tahapan yang dilakukan dalam digitalisasi peta tersebut, yakni: register peta, perancangan data grafis, dan perancangan data tabular.

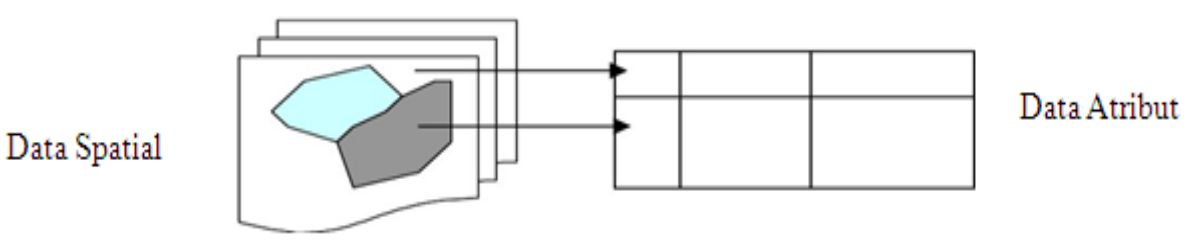

Gambar 3: Data Spasial dan Attribut

Dalam melakukan pengolahan data-data yang digunakan untuk perancangan Sistem Informasi Geografis ini ada beberapa prosedur atau tahapan-tahapan yang harus dilakukan, diantaranya:

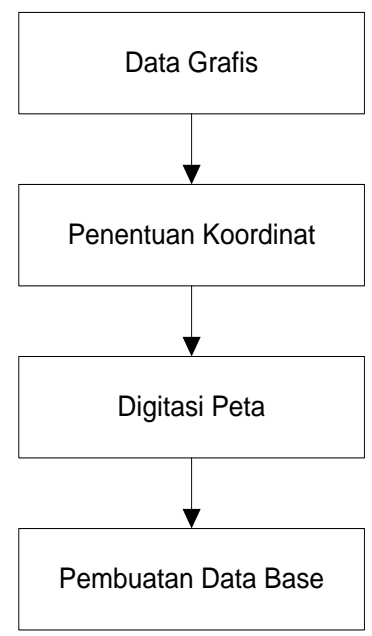


Gambar 4: Alur Pengolahan Data Spasial

Dalam proses digitasi peta database atau data atribut selalu berkaitan dengan data spasial, karena data atribut yang akan memberikan informasi tentang data spasial. Sehingga akan membentuk suatu integrasi data yang membantu para pengguna (user) untuk mendapatkan informasi yang mereka butuhkan. Dalam hal ini penulis menggunakan database yang merupakan database bawaan yang telah disediakan oleh MapInfo dengan format penyimpanan *.TAB. Berikut merupakan data-data yang dikumpulkan untuk perancangan system ini. Data yang diperoleh akan dikelompokkan menjadi data-data atribut kedalam sebuah tabel dengan menjadikan beberapa field. Berikut merupakan table data-data yang disajikan:

Tabel 1 : Data Base Jarak

\begin{tabular}{cc}
\hline Nama Field & Tipe Data \\
\hline Id & Character[50] \\
Arah & Character[50] \\
Jarak & Character[50] \\
\hline
\end{tabular}

\subsection{Perancangan Model}

Aplikasi ini dirancang menggunakan alat bantu berupa UML (Unified Modelling Language) agar mempermudah memindahkan konsep sistem yang dirancang ke dalam bentuk program, dimana perancangannya digambarkan dalam bentuk diagram-diagram berikut :

\subsubsection{Activity Diagram}

Activity diagram Menggambarkan aliran fungsionalitas dalam suatu sistem. Activity diagram menunjukan tahapan, pengambilan keputusan dan percabangan. Kelebihan dari activity diagram adalah kemampuannya dalam menampilkan aktivitas. Activity diagram digunakan untuk memodelkan aspek dinamis dari system yang memperlihatkan alur kendali dari suatu aktifitas ke aktifitas lain. Untuk lebih jelasnya 


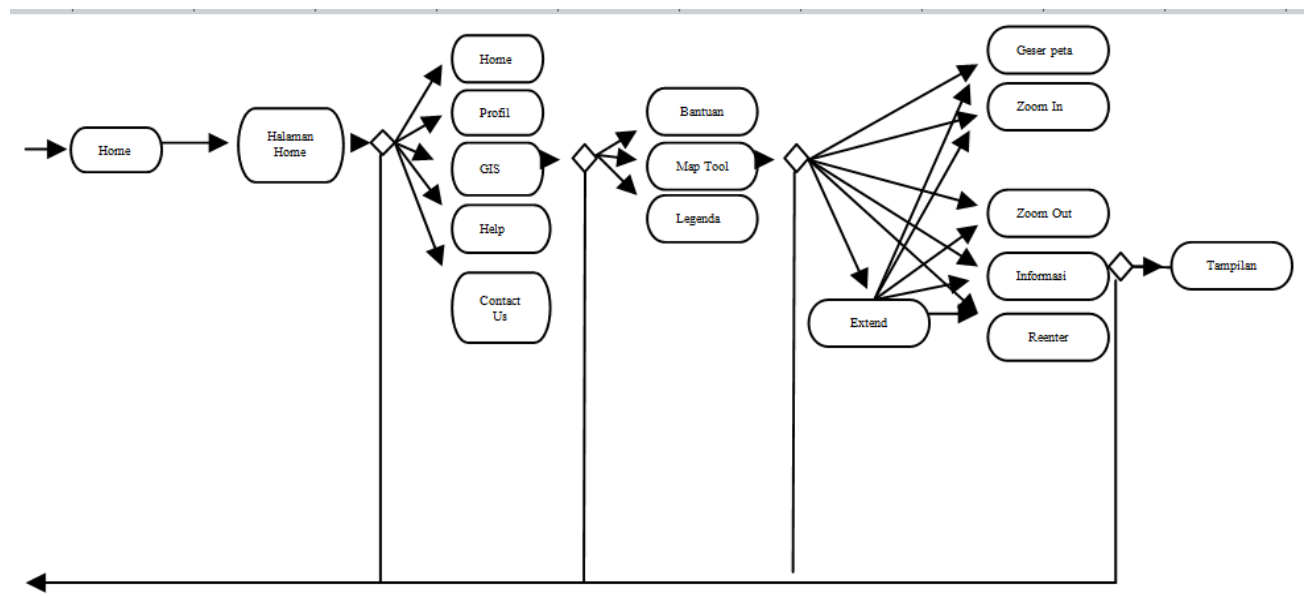

Gambar 5: Activity Diagram

\subsection{Implementasi dan Pengujian}

Logika Algoritma Floyd-Warshall pencarian evakuasi optimum:

1) $\mathrm{W}=\mathrm{W}_{0}$

2) for $\mathrm{k}=1$ then $\mathrm{n}$, do : for $\mathrm{i}=1$ then $\mathrm{n}$, do : for $\mathrm{j}=1$ then $\mathrm{n}$, do:

if $\mathrm{W}_{[\mathrm{i}, \mathrm{j}]}>\mathrm{W}_{[\mathrm{i}, \mathrm{k}]}+\mathrm{W}_{[\mathrm{k}, \mathrm{j}]}$ ganti $\mathrm{W}_{[\mathrm{i}, \mathrm{j}]} \mathrm{keW}[\mathrm{i}, \mathrm{k}]+\mathrm{W}[\mathrm{k}, \mathrm{j}]$.

3) $\mathrm{W}^{*}=\mathrm{W}$.

Keterangan :

$\mathrm{W}_{0}=$ matrik yang terhubung dengan graf berarah awal $\mathrm{W}^{*}=$ matrik minimal.

$\mathrm{W}_{\mathrm{i}, \mathrm{j}}=$ lintasan tercepat dari titik $\mathrm{v}_{\mathrm{i}} \mathrm{ke} \mathrm{v}_{\mathrm{j}}$

Algoritma Floyd-Warshall tersebut menghitung semua perlintasan terpendek, dan tidak menjelaskan bagaimana path terpendeknya. Untuk menentukan path yang menghasilkan jarak terpendek, maka harus ditambahkan matriks bujur sangkar $\mathrm{Z}$ (ukuran $\mathrm{n}$ x n) yang disusun sebagai berikut:

$\mathrm{Z}(0) \mathrm{i}, \mathrm{j}=$ 
Iterasi ke-k, jika titik vkdimasukkan antara titik-i dan titik-j (berarti menukar Wi,j dengan Wi,k + Wk,j), maka diganti Zi,jke Zi,k. Agar lebih efisien, penggantian matriks $\mathrm{Z}$ dilakukan bersama dengan iterasi pencarian jarak terdekatnya. Berikut Algoritma Floyd-Warshall dengan melibatkan jalur terdekat, adalah sebagai berikut:

1) $\mathrm{W}=\mathrm{W} 0 ; \mathrm{Z}=\mathrm{Z} 0$

2) for $k=1$ then $n$, do: for $i=1$ then $n$, do : for $j=1$ then $n$, do:

if $W[i, j]>W[i, k]+W[k, j]$ then

a. Tukar $\mathrm{W}[\mathrm{i}, \mathrm{j}]$ dengan $\mathrm{W}[\mathrm{i}, \mathrm{k}]+\mathrm{W}[\mathrm{k}, \mathrm{j}]$. b.Ganti Zi,j denganZi,k

3) $\mathrm{W}^{*}=\mathrm{W}$.

Keterangan :

$\mathrm{W} 0=$ matrikshubungan graf berarah berbobot awal $\mathrm{W}^{*}=$ matriks keterhubungan minimal

$\mathrm{Wi}, \mathrm{j}=$ lintasan terpendek dari titik vi ke vj

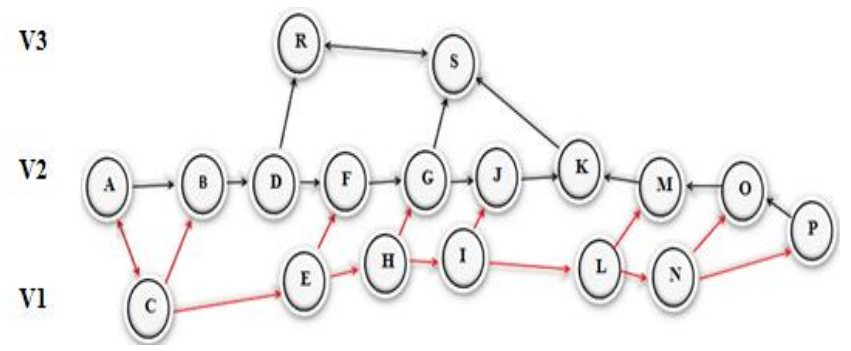

Gambar 6 : Node

Keterangan :

V1 = Zona Merah / Zona Bahaya

V2 = Zona Kuning / Titik aman sementara

V3 = Zona Hijau / Zona aman

Pembagian Zona : 
Heri Yanto, Romi Wijaya, Gisky Andria Putra

Zona merah : $3-5 \mathrm{~km}$

Zona Kuning : 8-10 km (karena pada km ke 5-7 disebut sebagai titik aman sementara)

Zona Hijau : $10 \mathrm{~km}$

Keterangan zona :

X : Zona Merah(zona bahaya)

RR : Zona Kuning(tujuan evakuasi sementara )

Y : Z Zona Hijau(zona aman)

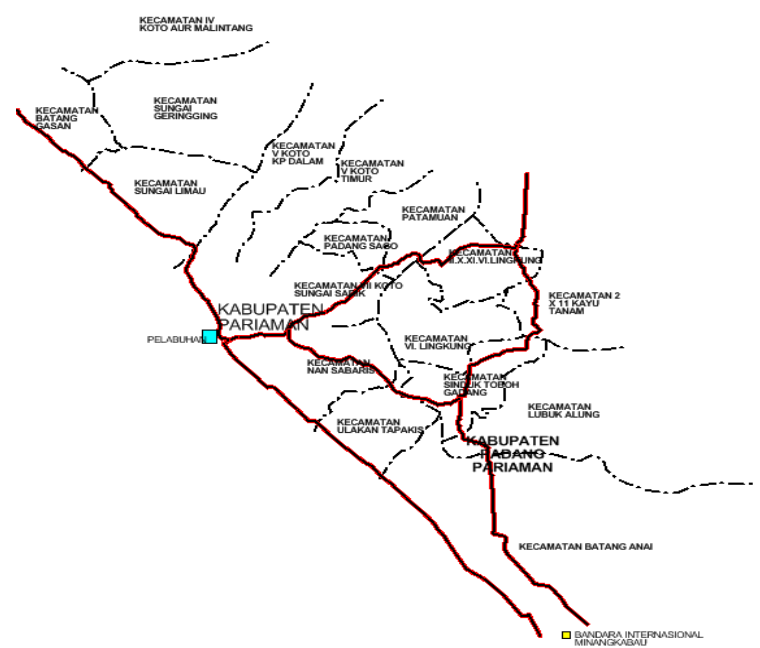

Gambar 7: Jalan Utama Padang Pariaman

Pada tahap selanjutnya untuk managemen pemetaan jalur evakuasi pasca bencana alam di kabupaten padang pariaman, dapat dilihat pada gambar 4. Titik warna merah merupakan zona merah atau titik awal dengan radius antara $0-5 \mathrm{~km}$, untuk mengarah pada titik kuning 
yang merupakan titik aman sementara dengan radius antara $5 \mathrm{~km}-8 \mathrm{~km}$, dan titik hijau merupakan daerah aman dengan radius $8 \mathrm{~km}-10 \mathrm{~km}$. Pada gambar 4 membentuk jaringan jalan dengan 18 node(titik) utama. Node-node tersebut kemudian di gabungkan dan dihitung jumlah edgenya.Tentu harus memperhitungkan aspek kelebaran jalan dan daerah jalan karena jalan yang dipilih harus memiliki ketentuan yang ada di teknik optimalisasi. Namun hal yang paling penting adalah menumbulkan social capital kepada masyarakat tentu dengan pamphlet-pamlet dan slogan yang di pasang di media baik cetak maupun digital, agar masyarakat yang berada di daerah padat penduduk khususnya di daerah pantai padang pariaman dapat memehami betapa bahaya yang mengincar sewaktu-waktu, dan dengan adanya himbauan kepada masyarakat tersebut masyarakat lebih mempunyai jiwa sosial yang tinggi tanpa mementingkan ego untuk menyelamatkan diri masing-masing, Sehingga menimbulkan kepanikan dan bahkan bisa memakan korban lebih banyak. Untuk lebih jelasnya tentang jalur evakuasi dapat dilihat pada gambar dibawah ini.

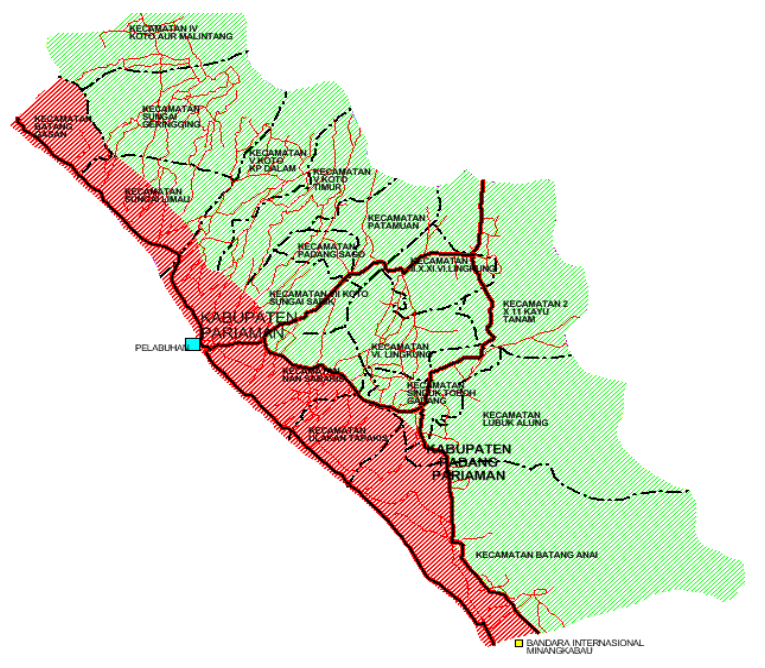

Gambar 8 : Batas evakuasi Pasca Bencana

Pada gambar diatas menjelaskan tentang batas aman wilayah dan bisa dijadikan sebuah acuan untuk sampai ke zona kuning atau zona aman sementara, ketika pasca bencana dan kemungkinan akan menimbulkan bencana susulan.

\section{Kesimpulan}

Kesimpulan dari penelitian evakuasi pasca bencana alam dipadang Pariamn adalah, menggiatkan memberikan edukasi kepada masyarakat tentang pentingya simulasi dan pemahaman cerdas bencana.Menumbuhkan sosial capital kepada masyarakat agar dapat memaksimalkan jalanya evakuasi.Karena disaat terjadi bencana animo masyarakat lebih 
kekepanikan tanpa memikirkan kepentingan social hingga kepentingan pribadipun sulit untuk didapatkan karena terlalu berebut untuk menyelamatkan diri.Lebih menggiatkan lagi sosialisasi kepada masyarakat pentingya tanggap bencana sebelum dan sesudah terjadinya bencana alam.

\section{Referensi}

[1] Yanto,H.(2018).SISTEM INFORMASI GEOGRAFIS TEMPAT IBADAH BERBASIS WEB MENGGUNAKAN ALGORITMA FLOYD WARSHALL(STUDI KASUS DI WILAYAH MERANGIN).In Majalah Ilmiah INTI (Vol.13).

[2] Yanto,H.(2018).OPTIMALISASI JALUR EVAKUASI MENGGUNAKAN SISTEM INFORMASI GEOGRAFIS DIKOTA PADANG BERBASIS WEB.Jurnal Sains Dan Informatika, 4(2),193.

[3] Admin. 2008. Pengenalan ArcView. Dikutip dari http://bpdasctw.info. [Diakses 23 Maret 2013].

[4] Aini, A. 2007. Sistem Informasi Geografis Pengertian Dan Aplikasinya. Diakses Dari http://stmik.amikom.ac.id/[Diakses 24 Maret 2013].

[5] Prahasta, Eddy. 2014. Sistem Informasi Geografis:Konsep Dasar Perspektif Geodesi \& Geomatika. Informatika, Bandung.

[6] Admin. 2008. Pengenalan ArcView. Dikutip dari http://bpdasctw.info. [Diakses 23 Maret 2013].

[7] Aini, A. 2007. Sistem Informasi Geografis Pengertian Dan Aplikasinya. Diakses Dari http://stmik.amikom.ac.id/[Diakses 24 Maret 2013].

[8] Prahasta, Eddy. 2014. Sistem Informasi Geografis:Konsep Dasar Perspektif Geodesi \& Geomatika. Informatika, Bandung.

[9] MADCOM, 2005. Aplikasi Pemetaan Dan Database Dengan MapInfo Professional7.5. Andi, Yogyakarta.

[10] Yanto.H.(2019). Managemen Pemetaan Sistem Informasi Geografis Distribusi Lahan Terbuka Pasca Bencana GempaBumi Kab. Padang Pariaman.SNTIKI11.11 